\title{
Breaking frame and frame-shifting in Bassem Youssef's satirical TV show al-Bernāmeg
}

\author{
Mohamed Mifdal \\ Chouaib Doukkali University, El Jadida, Morocco \\ mifdal.m@ucd.ac.ma
}

\begin{abstract}
This paper reviews how humor is made in terms of three theoretical models. First, it draws on the contribution of the structural semantics to the understanding of the text of the joke, especially the related notion of isotopy and the linear organization of the text of the joke. Second, this paper discusses humor in light of the Semantic Script Theory of Humor (SSTH), and the General Theory of Verbal Humor (GTVH). Third, this paper draws also on two pragmatic and discursive approaches, namely Grice's cooperative principle, and Simpson's model of satire as a discourse. This paper argues that semantic incongruities and their resolutions, as well as the violations of the cooperation principle can be best apprehended in light of the frames theory as developed in social sciences by Erving Goffman and frameshifting theory as it has been developed by Seana Coulson. The aim of this paper is to reveal the mechanism used to produce humor and laughter in one of the most popular satirical shows in the Arab world, Bassem Youssef's al-Bernämeg. The focus is not only on what humor/satire does (ridicule, mockery, attack of targets, overstepping of boundaries...), but also on how it does it (violation of codes, breaking frames, frame-shifting, conceptual blending) and why these discursive strategies are used (implications in light of historical and cultural context). This paper also argues that the generation of humor can be based broadly on breaking frames, which is inclusive of incongruity (both verbal and contextual), but studied in a multimodal content where incongruity is based on breaking and shattering frames that are constructed in verbal and visual forms. Humor generation is conducted through a continuous chain-like process of building, shattering, and rebuilding frames. It also deals with the frame-shifting and conceptual blending mechanisms at the level of interpretation and the construction of the meaning of humor. The aim is to account for the creative and flexible use of language for satiric purposes and thus to enhance the ability of traditional frame-based systems, including script-opposition theory to account for such flexibility in light of context and with reference to background.
\end{abstract}

Keywords: satire, humor, frame breaking, frame-shifting, conceptual blending. 


\section{Introduction: frames and breaking frame}

The aim of this paper is to review the incongruity-based theories of humor and to suggest a new model of the study of humor in terms of the notions of "breaking frame" and "frameshifting" as they can account for the different types of humor, as discourse event, in multimodal forms. The notion of frame has been widely used in cognitive psychology, artificial intelligence, and social sciences since 1970's, and it has been widely accepted that there is no human signifying act, no meaningful perception, cognition, and communication without "frames". Charles Fillmore defines the term "frame" as a knowledge structure:

By the term frame I have in mind any system of concepts related in such a way that to understand any one of them you have to understand the whole structure in which it fits; when one of the things in such a structure is introduced into a text, or into a conversation, all of the others are automatically made available.

(Fillmore 1982: 111)

Erving Goffman introduced the notion of "breaking frame" in his book Frame Analysis (1986), where he is most concerned with how individual experience is organized in terms of some "frameworks or schemata of interpretation of a kind that can be called primary" (Goffman 1986: 21). These primary frameworks are natural and social, they first identify occurrences that are unguided while the second "provide background understanding for events that incorporate the will, aim, and controlling effort of an intelligence, a live agency, the chief one being the human being" (Goffman 1986: 22).

Though this book is concerned with the micro-sociological organization of the human experience, it gives insights on how social behavior is guided and subjects the individual to some standards, appraisal, and continuous corrective control (Goffman 1986: 22). Since all social frameworks involve rules, they are liable to be broken in different circumstances and with different meanings. Breaking frames may reveal some kind of dissatisfaction or critique of the existing frames and norms.

Using frame analysis brings into light both the ways frames organize and control human experience and social conduct, and the ways these frames can be put into question. When frames are used in a playful way, they can generate humor for multiple ends: as social corrective (Bergson 2014) as when people laugh "when confronted by a person who does not sustain in every way an image of human guidedness" (Goffman 1986: 39), and as relief from tension and inhibitions (Freud 1905), as break from control (Bakhtin 1984), as intellectual subversion (Griffin 1994), or as cultural resistance (Scott 1990).

We would like to give an overview of the linguistic, pragmatic, and discursive theories of humor to highlight the possibility of bringing together the different mechanisms that account for humor generation under the notion of "breaking frame". Script-oppositions theories are more concerned with verbal humor and with the linear sequence of events. Though the notion of script was developed by analogy to the notion of frame, Brown and Yule (1983) argue that these notions are not the same. While scripts "deal with event sequences" (241), frames are "knowledge [...] stored in memory in the form of data structures" (238). As we are dealing with a multimodal discourse, the notion of frame "provides an attractive metaphor for thinking about discourse understanding as, at least partially, a process of fitting what one is told into the framework established by what one already knows." (Brown 1983: 239.) The notion of frame is not limited to action-oriented scripts but extends its scope to include the interpretation of discourses, and related notions and ideas. 


\section{Theories of humor}

\subsection{Isotopy disjunction model}

Violette Morin's model analyzes the text of a joke in terms of three functions: normalization, interlocking, and disjunction. Normalization puts the characters in their situation, interlocking establishes the problem to be solved or the question to be answered, and disjunction solves the problem humorously (Morin 1966: 108). While the first function establishes the context for the text of the joke, the second function introduces the problem to be solved or the question to be answered and thus creates expectations. In verbal humor, this function contains a connector which enables the switch between the two senses or isotopies. The third function concludes the narrative and contains a disjunctor that enables the passage from one sense to another. This passage produces a humorous effect by creating an expectation for one sense and actualizing another sense which are both potentially included in the connector.

The following joke (cited in Attardo 1994: 97) illustrates this passage from one sense to another:

Q: Do you believe in clubs for young people?

A: Only when kindness fails.

The word "clubs" is polysemous and acts as a connector while the phrase "kindness fails" is the disjunctor which redirects the meaning from "an organization of people" to "stick", and creates a humorous effect. The incongruity between the two meanings creates a tension that needs a resolution by the processor of the joke. It is this resolution which creates a sudden effect of humor.

Almost all the linguistic theories that were elaborated by humor scholars in the 1980's and 1990 's were incongruity-based, viewing humor as the result of an opposition between two senses, or alternatively scripts.

\subsection{The Semantic Script Theory of Humor (SSTH)}

The semantic script theory was outlined and developed by Raskin (1979/1985) and later by Attardo (1994). The central hypothesis of this theory is described as "elegant in its simplicity" by Paul Simpson who summarizes it as follows:

For a text to be a joke, it needs to satisfy two basic conditions. The first is that the text has to be compatible, fully or in part, with two different scripts. The second is that the two scripts with which the text is compatible are opposite in a special sense. And it is that special relation of script oppositeness which provides the main ingredient in the generation of a single joke carrying text.

(Simpson 2003: 30)

The basic notion of this theory is the "script", which can be defined, in the broadest sense, as "an organized chunk of information about something" and it is precisely "a cognitive structure internalized by the speaker which provides the speaker with information on how things are done, organized, etc."(Attardo 1994: 198.)

As the script is a knowledge structure that has a prior existence in the minds of the speaker and the processor of the joke, the script is expectation-based, which means that when a script is introduced, almost the same expectations are raised in the minds of the speaker and hearer or processor of the joke. The first script is opposed in a special sense to a second script that is immediately introduced. This script oppositeness generates a tension that the processor 
of the joke has to resolve by coming to grips with the incongruity between the two scripts and activating the script that is relevant for the joke to be actualized and humor to be generated.

To take an example from Raskin:

"Is the doctor at home?" the patient asked in his bronchial whisper.

"No," the doctor's young and pretty wife whispered in reply. "Come right in."

(Raskin 1985: 100)

The text of the joke is compatible with two scripts (doctor and lover); the linguistic analysis of the joke proceeds by using what Raskin called "the combinatorial rules" which allocate some lexical items in the joke, which are sub-domains, to larger scripts. Thus, the set of sub-domains activated by the lexical items "doctor", "patient", and "bronchial" allocate them to the medical script. As the joke progresses, the lover script is activated by the lexical items "wife", "whisper", "come", "in", "young", and "pretty". The combinatorial rules produce inferences, namely that the doctor is not at home and if the patient comes into the house he will not see the doctor. What the processor of the joke will discover is then the lover script, reinforced by the second set of sub-domains mentioned earlier.

\subsection{The General Theory of Verbal Humor (GTVH)}

The semantic script theory was revised and modified in later works by Raskin and Attardo and while the concept of incongruity through script opposition was retained, three ordered stages in the production of a comic text were developed from earlier scholarship on incongruityresolution theories of Suls $(1972,1977)$ and Schultz $(1974,1976)$ :

1 - setup

2- incongruity or script opposition

3- resolution

(Simpson 2003: 37-38)

The setup phase precedes the incongruity phase chronologically; it prepares the groundwork for the joke "by establishing an accessible, neutral context which is congruent with the experience of the receiver of the text" (Simpson 2003: 38). Simpson argues that "The concept of incongruity remains largely semantic in its conceptualization, but the notion of "script opposition" itself is enlarged to account for additional cognitive-psycholinguistic oppositions." (38). Drawing on Attardo, Simpson explains that "What is especially significant in Attardo's revisions is that the two scripts of a joke bearing text are ordered such that the first is highly accessible and based on a neutral context whereas the second, opposed script is much less accessible and is strongly context dependent." (38) The third phase is the resolution of incongruity which requires, according to Raskin and Attardo, a local logic mechanism. This mechanism functions by preserving in "working memory" "the multiple scripts projected by the incongruity for a period of time necessary for the search of a cognitive rule capable of solving the incongruity" (Attardo 1997: 412).

In all the three theoretical models introduced so far, there is always a sudden switch from one sense or script to another. The first is always introduced and activated as a context for the joke creating expectation as to how the text should be interpreted. The sudden switch to another script creates an ambiguity due to some incongruity between the two scripts. The resolution of the incongruity is achieved in terms of a local logic mechanism according to which the processor/receiver juxtaposes the two scripts and chooses the one that is relevant to the specific context of the joke. 
The introduction of context by the last theory is a new compelling element as will be shown by the next theory where the pragmatic element will be foregrounded. The specificity of the context of the resolution foregrounds the role of the processor/receiver of the joke in activating the effect of the joke in terms of its specific context (as opposed to the neutral context of the set-up).

\subsection{Humor as violation of the cooperative principle}

If the previous theories of humor view humor as the effect of text-based incongruity opposition, Grice sees humor as an effect of the violation of one of the four maxims of the cooperative conversational principle. These maxims are quantity, quality, relation, and manner; the deliberate flouting of any of these maxims generates humor because this flouting breaks a well-established principle of successful conversation. Pan argues that "His cooperative principle is based on the assumption that language users tacitly agree to cooperate by making their contributions to the talk as is required by the current stage of the talk or the direction into which it develops" (2012: 21).

Let me discuss one example to illustrate the flouting of such maxims:

An old lady was strolling through the park when she saw Jamie with a dog. "Does your dog bite?" she asked. "No." said Jamie. When the old lady tried to pet the dog, it almost bit her finger off. "I thought you said your dog doesn't bite!" screamed the old lady with blood dripping from her hand. "That's right," answered Jamie, "My dog doesn't bite, but that's not my dog."

(Pan 2012: 22-23)

In this joke the maxim of quantity is flouted because when the old lady asks Jamie whether her dog bites, Jamie gives less information than needed or expected. The woman assumes that the dog she is trying to pet is Jamie's dog, and the dog bites her finger. The woman thinks that Jamie has lied to her, which is partly true according to the cooperative principle which entails that a speaker should give enough information to avoid such misunderstanding.

Another example further underlies the role of violation of the cooperative principle in generating humor:

A very shy guy goes into a bar and sees a beautiful woman sitting at the bar. After an hour of gathering up his courage, he finally goes over to her and asks tentatively, "Um, would you mind if I chatted with you for a while?"

To his surprise, she responds by yelling, at the top of her lungs, "No, I won't sleep with you tonight!"

Everyone in the bar is now staring at them. Naturally, the guy is hopelessly and completely embarrassed and he slinks back to his table. After a few minutes, the woman walks over to him and apologizes. She smiles at him and says, "I'm sorry if I embarrassed you. You see, I'm a graduate student in psychology and I'm studying how people respond to embarrassing situations." He responds, at the top of his lungs, "What do you mean $\$ 200$ ?"

(Pan 2012: 24)

The humor is generated in this joke by the violation of the maxim of manner and the maxim of relevance as the woman's speech is ambiguous and irrelevant from the man's perspective, and she seems to fail to cooperatively follow these maxims. In response, the man violates the same maxims to embarrass her as much.

These two examples evince how a violation of a principle or a pragmatic norm can generate humor in the same way the deactivation of a script and the sudden switch to another 
one do. What sustains the generation of humor in both models is the sudden transformation of an expectation and the creation of an incongruity between what has been expected and what is actually happening or being activated. When two people engage in a conversation, they cooperate to make their conversation successful and effective. When this cooperative principle is violated, humor can be one of the possible effects of this violation. What is actually violated is an expectation sustained by a social, pragmatic norm.

\subsection{Satirical humor as a discourse}

Paul Simpson builds on these linguistic and pragmatic approaches to address satire as verbal humor organized in a higher order of discourse. He retains the principal notions of the linguistic theories, namely the set-up and the script-opposition incongruity, but reorganizes the practice of humor in satire insofar as it includes and makes salient three discursive subject positions: the satirist, the satiree, and the satirized (Simpson 2003: 86). He argues that satirical discourse has four components: the setting, the method, the uptake, and the target (Simpson 2003: 70). The setting is "essentially a non-linguistic component covering the preparatory preconditions necessary for the construction of satirical discourse" (Simpson 2003: 70). This means that the setting is dependent on the interactive context, and it is an initial principal reference to the knowledge structures, beliefs, and attitudes of the satirist and the satiree. The method consists of two phases: the setup which establishes an accessible neutral context and an incongruity phase activated by the script opposition.

The activation of incongruity is achieved through discursive strategies like exaggeration, grotesque, caricature, inversion of scripts, transition between positive and negative polarities, the alternation between normal and abnormal scripts and finally by the opposition between possible and impossible discourse worlds. The uptake is the inferences required for the resolution of the incongruity created by the method. This entails the understanding of the illocutionary force and the perlocutionary effect (Austin 1962) of the satirist discourse by the satiree. The satirical target can be episodic, referring to a specific event, personal, attacking a particular individual, experiential, directed toward certain aspects of human conditions, or textual, spotlighting the linguistic code as object of attack.

However, the construction of the satiric discourse requires the combination of two elements: the prime which accounts for the process by which one particular contextual frame becomes the main focus of attention for the reader, and the dialectic which is a text-internal element that creates an opposing idea or movement (Simpson 2003: 88). The struggle between the prime and the dialectic creates a force that leads to the resolution which creates a new idea irreducible to any previous elements in the argumentation.

\section{The relevance of "breaking/shifting frame"}

These different humor theories reveal some development since most of them base the generation of humor on a rupture of an initial process of interpretation and expectations. According to Kant, "Laughter is an affection arising from sudden transformation of a strained expectation into nothing" (Kant 1957:177). This sudden transformation has been given different labels, be it disjunction, deactivation, switch, twist, or violation. This rupture is often triggered by an incongruity that is due to an opposition between what is initially expected and what is suddenly introduced later in the text. In search of a more updated approach, the notions of "breaking frame" and "frame-shifting" might look much more appropriate to account for the mechanisms of humor generation and enables the convergence of all the previous theories and mechanisms. 
The word "frame" can be used as a cover term for a variety of concepts such as script, scenario, cognitive model, and schema, and the breaking of frame and frame-shifting can be used to refer to the act of moving abruptly from an initial mental structure and attendant interpretation to an unexpected and totally different mental structure or another interpretation of the initial structure. While this paper uses breaking frame to account for what the humorist does to generate humor, it refers to the notion of frame-shifting (Coulson 2001) to account for the ways humorous meaning is constructed by the audience. The movement from an initial meaning or frame to another frame or interpretation of the initial meaning or frame is construed as a break at the level of production or generation of humor; however, this movement is labeled as a "shift" at the level of interpretation by the audience. The producer of humor breaks the initial frame and invites the audience to shift frame in order to get the humorous effect.

Coulson (2001) conducts a revision of the original frame-based systems and compositional approach to meaning construction by highlighting their shortcomings. She argues that frame-based systems are brittle because scripts are "rigid data structures and cannot accommodate events that are out of the ordinary." (83.) Drawing on Minsky (1975), she uses his definition of frame as "a data structure used to represent commonly encountered, stereotyped situations" (19) with slots and fillers. Activating a frame creates expectations about the main aspects of the event by inviting the agent to fill the slots retrieving the needed elements from the long-term memory. However, in case the information is unavailable, the slots are filled with default values. When this process produces nonce senses, the initial frame is abandoned and a new frame is created (frame-shifting) drawing on background knowledge and larger context to overcome ambiguities and indeterminacy in meaning construction. In a compositional approach to meaning construction, the meaning of construction system consists of word meaning and syntactic structure. Even if this meaning creates a certain frame, the latter remains abstract and does not account for unusual meanings, ambiguities, and indeterminacy. It is therefore necessary to make inferences by doing a pragmatic reanalysis to provide the correct meaning of an utterance.

Coulson (2001) calls this process of active creation of meaning "on-line construction of meaning" (29) and argues that this construction "is not a matter of manipulating preexisting representations from memory, but rather an active process in which the speaker integrates aspects of perceptual and conceptual information with more abstract information available from long-term memory" (29). Cross-domain mapping, conceptual blending, and frameshifting are processes used to "enhance the explanatory adequacy of traditional frame-based systems." (30.) Frame-shifting is prompted by a violation of slot-filling constraint when a default value does not solve the ambiguity. It is a pragmatic reanalysis that consists in creating a new frame that makes sense of the utterance. This process also involves making connection (mapping) between different domains and blending concepts in terms of linguistic and nonlinguistic information, and adequate background knowledge (including culture-bound information).

Coulson's constructivist approach to meaning construction highlights the productive language behavior that takes into account the creative non-compositional mechanisms of meaning construction. Humorous structures are based on a shift of frames and are "deliberately constructed to violate the listener's expectations." (Coulson 2001: 49.) This approach suggests that people can go beyond knowledge of the typical to construct creative nonconventional meanings.

The frame breaking and frame-shifting will inform our analysis of the mechanisms of humor generation and reception in the TV program al-Bernāmeg. However, a brief account of the political and historical context will frame humor within the specific context of the humor in this post-Arab Spring TV program in Egypt. 


\section{Political satire in post-Arab Spring Egypt}

Adopting an interactive approach to apprehend the workings of satire through breaking frame that is inclusive of reception (audience's response) entails an understanding of the social, political, and moral norms, in the name of which satire becomes operational. Throughout human history, satirists have contributed meaningfully to the moral and political discourse. Most critics agree that the relationship of satire to power is problematic, but they tend to disagree whether the power of satire can seriously subvert the dominant political order or change the historical reality in an effective way by toppling dictatorships or changing the political regimes, for example. The controversial reception of the TV satirical show alBernāmeg, aired first on CBC, has brought to light the new state of satire in the Arab World, especially in Egypt, since the 2011 uprising. Paradoxically, "politicians are more suspicious of satirists and set more boundaries to their satire" (Mifdal 2013: 1).

After Morsi had been elected president of Egypt (June 30, 2012), Bassem used satire to criticize him during his one year in office and was sued by Morsi's supporters for insulting the president and Islam. After a brief detention, Bassem was freed and his satirical show rose to global prominence. The number of Youssef's followers on Twitter exceeded the number of President Mohammed Morsi's followers. Analysts claim that Bassem's satirical show had largely contributed to the deterioration of the political image of the Muslim Brotherhood and the rapid fall of Morsi. This claim seems vulnerable to several objections. First, the opposition to Morsi's rule was strong enough to undermine his political endeavors. Second, the economic situation was rapidly deteriorating, leading to a decrease in popularity for the president even among those who had voted for him. Third, the president's political mistakes were just fatal.

As a liberal, Bassem echoed critiques of Morsi's rule made by a large number of political parties, minorities, and disappointed people. The growing critical acclaim that his satirical show received was in fact the expression of the vested interests of the anti-Islamist political elite and the Christian minority. It can be argued that Bassem is a liberal secularist who is strongly opposed to the Islamic fundamentalism and that his satire of Morsi can be apprehended, framed, and even justified in terms of this political stance. However, without the support of the political elite, Bassem's satire would have had little or no immediate effect. (Mifdal 2013.)

Bassem had taken advantage of the strong opposition to Morsi's rule to mount an attack at "what seemed then an easy safe target, and at the same time he had been used by the political elite to disparage the controversial president and undermine his policies". Bassem had been off air after Morsi's overthrow in July 2013 and his return to the airwaves on October 25, 2013 was a real litmus test both for his satire and for the free expression in the post-Morsi era. Questions were raised about whether Bassem's satire was really the symbol of a more tolerant democratic society willing to make fun of its foibles, whether Morsi was just too thin-skinned to tolerate playful criticism, whether the new rulers of Egypt would tolerate his satire, and whether Bassem would dare criticize the military and its leaders.

A lot of questions were asked during his four-month hiatus and the expectations changed in terms of political affiliations and interests. Bassem targeted the Islamists, the military and the zealous supporters of army chief Abdel-Fattah Sīsī in the name of democracy and civil liberties: "What we fear is that fascism in the name of religion will be replaced by fascism in the name of patriotism and national security", Youssef said. His mock news show was followed by hours of verbal jousting on social media over its content and supporters of both Morsi and Sīsī expressed displeasure. The CBC channel broadcast a statement on behalf of the channel's board to distance itself from Bassem's political stance and criticism of the military and its leaders: "CBC will continue to be supportive of the basics of national sentiment and popular will and is keen on not using phrases and innuendos that may lead to mocking national 
sentiment or symbols of the Egyptian state", CBC broadcaster said. (Kingsley 2013.) Four complaints were filed with the top prosecutor the next day, accusing Bassem of defaming the armed forces and belittling their efforts to fight terrorism.

Bassem was aware that he would be prosecuted by his new critics in an article he published before his return to $\mathrm{CBC}$ and described them as "those who love freedom dearly when it works for them". Now that the satirist was rejected by so many critics, a reassessment of the state of satire in Egypt was required. There were doubts whether Bassem would continue to challenge the new rulers of Egypt and whether his satire would have the same effects it had in the Morsi's era.

Political constraints have never been able to stop satirists from challenging authority. Drawing on Mathew Hodgart's suggestion that "no matter how totalitarian the regime, a miniscule degree of freedom will always remain sufficient for the production and dissemination of satire", Brian A. Connery argues that "political and/or cultural repression and oppression are often a stimulus to satire" (Hodgart 2010: 5). Satire thrives, then, in the face of repression and in the presence of risks. However, in a context of political reprisal, satirists look for protectors and patrons and tend to attack safe targets and eschew frontal opposition to strong power-holders.

It is within this context that Bassem's satire had to function and achieve effects. Without patrons or supporters, Bassem had to run the risk of being rejected and even prosecuted. Bassem has chosen to make his satire a form of resistance to systems of oppression and assume his fate as a liberal ironist and satirist in a repressive state.

\section{Al-Bernāmeg: The show of the show}

The use of the notions of "breaking frame", "frame-shifting", and "conceptual blending" to explain how humor is generated in media is meant to enhance the explanatory adequacy of frame-based system to account for the creative use of language by satirists and the combinatorial work their use of satire entails, namely their combination of linguistic elements, context, and background. In episode 2 season 3 of al-Bernāmeg, aired on Friday, February 14, 2014 (https://www.youtube.com/watch? $\mathrm{v}=\mathrm{mWB1qqTxY8U}$ ), Bassem Youssef does break the frame of the boundaries and expectations of normal TV news and introduces the humorous satirical mode as a new frame for the program (keying of a primary framework: serious news shows vs. non-serious news shows) as this program had started three years earlier and the audience were used to the satirical mode of the program. Actually the political reactions of the military powerholders of the time to al-Bernāmeg were antagonistic and threatening. When the program was aired, the audience expected Bassem to avoid talking about the military and especially Sīsī, the commander-in-chief; however, Bassem starts by greeting the audience, stops for a while and says in a challenging voice and gesture: "(E) Sīsī!!" (the emphasis (E) is Bassem's). The studio audience bursts into laughter as their strained expectations (and those of the large TV audience) turn into nothing and their fear that Bassem may step back is totally dissipated. The strained political situation and the numerous threats that Bassem Youssef received because of his audacious and politically incorrect satirical strategies framed the expectations of the audience. Fully aware of this situation, Bassem broke this frame of fear by insisting on targeting those who threatened him and shifted to the new frame of audacity and frontal attack of the existing regime.

From the outset, Bassem adopts an ironic tone and a satirical intent. He keeps building and breaking frames linguistically and visually. Bassem informs the audience that since February 14 is the day of love, he will talk about love, but not any love, the love of Egypt: "Egypt the mother, which means one nation, one heart, and one lap". Then he inserts and 
screens an excerpt from a TV program featuring a well-known politician saying: "which means one breast, one mother, and that's why Egypt is a mother and she can't be but a mother". The speaker uses his index finger to show that Egypt is united as one nation and insists on that; likewise, Bassem uses his index to produce the same effect but comments ironically:"one nation, one side (one breast), wait a minute... did he say one side? That's why it isn't enough for us all!". Bassem breaks the ironically serious frame of his talk about the love of Egypt by inserting an exaggerating assertion of the politician about Egypt as being a mother with one breast (a country with few resources). He uses this assertion to explain why it is not enough for all Egyptians. The initial frame (of loving one's country) is broken visually by the insertion of the visual excerpt, then by comparing Egypt to a mother with one breast and linguistically by using the politician's metaphor falsely, but to accurately point out the economic and political crisis ravaging the nation and the unequal distribution of wealth (the breast of the mother).

The speaker in the video clip uses conceptual blending to connect two concepts by analogy: one nation/one mother, to enhance the idea of unity. From this analogy (metaphor) emerges a cross-mapping structure where the source domain (one nation) is connected to a target domain (one mother) to make his argument of the necessity of unity among Egyptians. Bassem, on his part, alters the meaning of this metaphoric structure by changing the argument in both domains and creating a new frame of analogy between the concepts. He replaces the argument of unity by the argument of scarcity of resources. A new mapping has been at work to connect the scarcity of the resources with the inability of a mother with one breast to feed all Egyptians.

This frame-shifting generates humor by introducing a disjunctor (one breast which is indicative of an anomaly) and creating a new frame for the construction of the new meaning of scarcity. This shift implies that the resources of the country are not enough because the country is in a state of political disorder and the resources are exploited by the military. The on-line comprehension of this conceptual blending and frame-shifting is based on elements recruited from the political and social background of Egypt at that time of history.

Then he proceeds by saying that this nation is really preoccupied with an obsessive question: "who is the next president of Egypt?" This was a timely question after the elected president, Morsi, had been toppled, and the political vacuum was created by this military coup. Bassem inserts many excerpts featuring journalists from different TV shows asking the same question in different ways. He ironically concludes that "these people are asking strange questions, very difficult questions, no one knows how to answer them". The irony of his comment stems from the fact that it was unlikely that any politician would dare stand as a candidate in the next elections because of the strong power of the military. Bassem is falsely raising expectations about the possibility of a candidate standing in the elections against Sīsī. However, Bassem breaks the frame of such expectations by inserting a negative of a photo of Sīsī. The audience laughs and claps in recognition of the identity of the person in the negative. Bassem maintains the same ironic tone and says: "Who is the next president of Egypt?! This is a supernatural question. Are we going to resort to astrology!"

Keeping the same negative (of a photo) in a side screen, he keeps inserting excerpts in which the same question is asked and nobody, including the minister of culture, can answer it. However, though they cannot give the name of the next president of Egypt, most speakers mention some of his qualities (patriotic, proud, charismatic, educated, has a CV...) but none dares name him as Sīsī. Bassem maintains the initial frame that he shares with the audience that everyone knows that the person in the negative is $S_{1} \bar{s} \overline{1}$, then he says that thanks to these answers, the identity of the next president is clear and addresses those who were interviewed: "Are you afraid of giving his name?!" At the time when everyone is expecting Bassem to show the photo of Sīsī, he breaks the initial frame ( $\mathrm{Sī}_{\bar{s}} \overline{1}$ as the favorite candidate and the 
connector to the first frame) and shifts visually to another frame again by showing the photo of the ex-coach of the Egyptian football team (the disjunctor that introduces an unexpected candidate), Hassan Shahata, generating a hilarious laugh among the audience. Laughter frees the audience of their fear of the powerful military regime and equally of their fear that the hopes for democracy and social change would be shattered by the return of autocracy.

It should be noted that Bassem's shifting of frames from the expected candidate to a totally unexpected candidate is ironic and aims at making fun of those journalists and politicians who pretend not knowing the real candidate. He is making fun of their fear and their inability to stand against this burgeoning dictatorship in the wake of Arab Spring.

The whole program is a series of building, breaking and shifting frames and the humor flows almost continuously. Actually, there is no one master frame and Bassem establishes incongruity mostly by aligning different frames into his own narrative and using other people's edited comments to frame his own argument. The ironic tone is maintained throughout the program and Bassem adopts the frames of his butts but suddenly distorts and breaks these frames. However, the resulting ironic stance raises expectations that are shared both by Bassem and his audience but becomes at times ambiguous, preparing the framework for a new break of the adopted frame and the initial expectations. For example, when Bassem inserts an excerpt from a program in which the journalist Mahmoud Saad suggests that the next president should have the qualities of Gamāl Abdenasser, he asserts that Egypt has witnessed two people of higher caliber. The audience that have become gradually aware of the ironic frame-shifting of his statements would expect the people being interviewed to name Sīsi and Gamāl Abdenasser as these two figures but has doubts about how Bassem will break this new frame of expectation and interpretation and shift to a new ironic frame. To the audience's surprise, the first interviewee, a young man, says: "Egypt has given birth to two great men, Gamāl and Abdenasser. I wasn't born then but these are the two men who built Egypt".

This answer is so hilarious and reveals how the masses are totally ignorant about politics and that they can be easily manipulated. Bassem's satire proceeds by adopting a frame and maintaining it for a while before shattering it into absurdity, then starting anew by creating a new frame from the remains of the broken frame in a way that it can allow the insertion of his butts' statements and using them for humorous ends. Bassem uses the absurd answer of the interviewee (absurd because Gamāl Abdenasser is one person and not two persons: Gamāl and Abdenasser) and tries to maintain his fallacious reasoning by building on it to produce more humor and laughter: "They are two men: Gamāl and Abdenasser. The (Egyptian) people is always divided by these two men. There are those who loved Gamāl and those who loved Abdenasser..." Bassem continues in the same tone until he feels that the humor starts to lose effect, and he suggests another political leader (belonging to the same political party of Gamāl Abdenasser), namely Hamdin Sabahi. After praising him ironically for a while, he inserts an excerpt from a video where we can hear Hamdin Sabahi asking the audience in a political assembly if someone has found a lost white iPad. The frame of ironic praise raises an expectation about a certain break and shift, but no one knows for sure how this is likely to be done. Bassem breaks the frame by juxtaposing a lost iPad with a lost dream of a whole nation: "The lost dream is not as important, it is a long-term process. We need to find the iPad first". Immediately after his ironic praise and drawing an ironic parallel between achieving the dream of a whole nation and finding a lost iPad, he uses the iPad to adopt another frame (that bears the seeds of bitter irony) in which revolution is associated with advances in technology: "Is there a revolution without iPad?". This very frame is broken immediately and the same happens continuously until the same topic is exploited fully to generate humorous effects and expose satirically the inability of politicians like Hamdin Sabahi to maintain the dream of a true democracy alive and challenge the military. 
Bassem insists on the absurdity of the political situation and makes it look so in a variety of ways. Inserting excerpts of videos is always preceded by some verbal preparation of the pre-conditions for the generation for the humorous effect. Bassem wants to know what will happen if another figure from the military stands as a candidate against Sīsī. The excerpt is an interview of a Sheikh (chief of a tribe) about his political attitudes. In response to a question about who he will vote for: Sīsī or Sami Annan (another military figure), the Sheikh answers: "I will vote for both"!!

Bassem: "We need someone from the military. Sīsī, or Annan.

Interviewer: What if they both run for president? Who will you vote for?

Sheikh: If they both run for president? - Yes... - I'll vote for both!"

Bassem's satirical humor is an accurate anatomy of the political situation in which the political leaders are represented as subordinated to an authoritarian military rule of Egypt after the great 2011 revolution that put an end to a long high-handed dictatorship, and the masses are really crippled by ignorance and can be easily manipulated. The satirical humor as has been analyzed earlier is based mainly on sustained irony that informs a continuous process of adopting/building, breaking and shifting frames in a multimodal ways where the verbal uses the visual to generate humor in the same way the caption generates humor in a caricature. It is worth noting that irony informs markedly the shift from the initial frame of expected meaning to a totally unexpected frame (the shift from the real candidate to the national football team coach as a potential candidate / the shift from the interest in the dream of a whole nation to the interest in a lost iPad are informed by irony and sarcasm).

The work of the satirist (Bassem and his team) is based on a prior selection of data that consists of news, reports and other TV shows. The selection is performed in terms of excesses and undemocratic practices that prevailed during the time of the episodes. The logic of the satirist processes the data with a view to revising the actual frames that inform them and give them meaning. The corrective revision (which is a form of political critique and resistance) is achieved through an instance of irony in which the dominant frames endorsed by the political regime in power are undermined and made fun of. The regime's claim of democracy and social change is put into question by highlighting its contradictions and by reframing the claim and revealing its falsity. Post-Arab spring political situation in Egypt has been as repressive as the previous one and the political manipulation of the masses was at its peak after the coup d'état that put an end to a democratically elected president. The economic situation has worsened and the hopes of social change have been completely shattered.

The aim of the satirist is morally sustained in that it consists in revealing the real situation where all the values of the revolution have been forsaken. The satirical irony that takes on a humorous, yet bitter and moral, stance ridicules the false claims of the power-holders. Shattering the frames that these power-holders use to justify the undemocratic practices of the military gives a moral blow to the latter and restores the values of democracy at least discursively taking advantage of the wide reception of the show al-Bernāmeg. The incongruity on which the satirical irony is based is context-dependent and is activated by the cooperation of the audience (the satiree of the show) that is fully aware of the existing chaotic reality and the false frames of the dominant discourse. These frames falsely structure the understanding of the masses claiming that the coup is a corrective restoration of democracy and an impetus for potential social change. Breaking frames and frame-shifting as an approach to the analysis of multimodal textuality reveals how the satirist holds to ridicule the discursive contradictions concealed by the dominant political discourse and its frames of interpretation by aligning the dominant frames and making them undergo the test of reality sustained and maintained by the audience and its laughter. 


\section{Conclusion}

This paper's aim was to provoke readers and critics into thinking about "breaking frame" and "frame-shifting" as an enhancement of the explanatory potential of frame-based systems and script-based approaches especially in the analysis of satiric humor. The constructivist approach that informs these two notions brings to light the productive and creative behavior of satirical humorists like Bassem Youssef in a multimodal context of representation and the political and cultural implications of such satirical discourse. The construction of meaning and effects in humorous, satirical structures should not be limited only to the linguistic analysis of how breaks and shifts are made but it should include their discursive implications in the larger pragmatic context of political contention and struggle. Understanding how humorists shift frames to generate humor requires linguistic knowledge while revealing the reasons that have motivated this shift is gained in terms of extensive pragmatic knowledge of specific discourses at play within the specific historical context of the target culture. Future research might study these breaks and shifts in the satirical discourse as strategies of revision and critique to draw attention to what does not work in the target's practices, institutions, and values.

\section{References}

Attardo, S. (1994). Linguistic Theories of Humour. Berlin: Mouton De Gruyter.

Attardo, S. (1997). 'The semantic foundations of cognitive theories of humour'. Humour: International Journal of Humour Research, 10 (4), pp. 395-420.

Austin, J. L. (1962). How to do Things with Words. London: Clarendon Press.

Bakhtin, M. (1984). Rabelais and His World. Trans. by Iswolsky, H. Bloomington: Indiana University Press.

Bergson, H. (2014). Laughter: An Essay on the Meaning of the Comic. Trans. by Brereton, C. \& Rothwell, F. Available online: www.templeofearth.com/ [Retrieved 4 June, 2014].

Coulson, S. (2001). Semantic Leaps: Frame-Shifting and Conceptual Blending in Meaning

Construction. Cambridge: Cambridge University Press.

Fillmore C. (1982). 'Frame semantics', in Linguistic Society of Korea (ed.), Linguistics in the Morning Calm. Seoul: Hanshin, pp 111-138.

Freud, S. (1905). Jokes and Their Relation with the Unconscious. Retrieved from Freebooks by www.SigmundFreud.net (2014).

Goffman, E. (1986). Frame Analysis: An Essay on the Organisation of Experience. Boston: Northeastern University Press. (Originally published by Harper \& Row in 1974.)

Grice, P. H. (1975). 'Logic and conversation', in Cole, P. \& Morgan, J., Syntax and Semantics. 3: Speech Acts. New York: Academic Press. pp. 41-58.

Hodgart, M. (2010). Satire: Origins and Principles (Originally published in 1969). New Brunswick, Jersey: Transaction Publishers.

Kant, I. (1957) The Critique of Judgement, trans. James Creed Meredith. Oxford: Clarendon Press. (Originally published in German in 1790.)

Kingsley, P. (2013). 'Egyptian TV Station suspends satirist Bassem Youssef's show'. Guardian.com. $\quad$ Retrieved on 2019: https://www.theguardian.com/world/2013/nov/02/egyptian-tv-bassem-youssef-cbcsuspends.

Mifdal, M. (2013). 'Bassem Youssef: A satirist on a razor's edge'. Morocco World News.

November 1. Retrieved: https://www.moroccoworldnews.com/2013/11/110813/bassemyoussef-a-satirist-on-a-razors-edge/. 
Minsky, M. (1975). 'Frame system theory', in Johnson-Laird, P. N. \& Wason, P. C. (eds.), Thinking: Readings in Cognitive Science. Cambridge, UK: Cambridge University Press, pp. 355-376.

Morin, V. (1966). 'L'histoire drôle'. Communications 8, pp. 102-119.

Raskin, V. (1985). Semantic Mechanisms of Humour. Dordrecht: Reidel.

Simpson, P. (2003). On the Discourse of Satire: Towards a Stylistic Model of Satirical Humour. Amsterdam: John Benjamins.

Shultz, T. R. (1974). 'Development of the appreciation of riddles'. Child Development 45, pp. $100-105$.

Shultz, T. R. (1976). 'A cognitive-developmental analysis of humour', in Chapman, A. J. \& Foot, H. C. (eds.), Humour and Laughter: Theory, Research and Applications. London: Wiley, pp. 11-36.

Suls, J. M. (1972). 'A two-stage model for the appreciation of jokes and cartoons: An information-processing analysis', in Goldstein, G. \& McGhee, P. (eds.), The Psychology of Humour. New York: Academic Press, pp. 81-100.

Suls, J. M. (1977). 'Cognitive and disparagement theories of humour: A theoretical and empirical synthesis'. In Chapman, A. J. \& Foot, H. C., It's a Funny Thing, Humour. Oxford: Pergamon Press, pp. 41-45.

Pan, W. (2012). 'Linguistic basis of humour: On uses of Grice's cooperative principle". International Journal of Applied Linguistics \& English Literature 1 (6), pp. 20-25. 